\title{
THE INFLUENCE OF CUTTING CONDITIONS ON SURFACE INTEGRITY IN HIGH FEED MILLING OF Ti-6AI-4V WITH SUPERCRITICAL $\mathrm{CO}_{2}$ COOLING
}

\author{
P. Litwa ${ }^{1}$, K.K. Wika ${ }^{1 *}$, A. Zonuzi ${ }^{1}$, C. Hitchens ${ }^{1}$ \\ ${ }^{1}$ Nuclear Advanced Manufacturing Research Centre, The University of Sheffield, Rotherham, United Kingdom \\ *Corresponding author; e-mail: k.k.wika@sheffield.ac.uk
}

\begin{abstract}
This study investigates the influence of cutting conditions on surface integrity in the milling of Ti-6Al-4V using various cooling methods: soluble oil coolant; supercritical carbon dioxide; and supercritical carbon dioxide with Minimum Quantity Lubrication. A Design of Experiments approach was used to evaluate a change in direction and interactions between the input factors and the responses. The results show a correlation between the residual stress and the longitudinal/transverse cross-sectional microstructures of the machined surface. It was observed that high-feed milling of Ti-6Al-4V with the assistance of supercritical carbon dioxide with Minimum Quantity Lubrication resulted in improved surface integrity. The opposite was found in terms of soluble oil coolant where some detrimental changes to the microstructure were seen.
\end{abstract}

\section{Keywords:}

Milling; Ti-6Al-4V; Supercritical carbon dioxide; Surface integrity

\section{INTRODUCTION}

Machining of difficult-to-cut materials such as titaniumand/or nickel-based super alloys is a challenge faced by industry [Pervaiz 2014]. The poor machinability of Ti-6Al-4V or Ni-based alloys is mainly caused by the low thermal conductivity of these alloys. Increasing tool wear consequently leads to tool failure and breakage. The challenge in high speed machining of Ti-6Al-4V and other heat-resistant super alloys is dissipation of the heat generated in the cutting zone. Currently, new advanced cooling strategies such as liquid carbon dioxide $\left(\mathrm{LCO}_{2}\right)$, supercritical $\mathrm{CO}_{2}\left(\mathrm{scCO}_{2}\right)$ or liquid nitrogen are being developed to increase tool life and maximise material removal rate (MRR) [Busch 2016]. Pušavec et al. (2019) reported that $\mathrm{CO}_{2}$ has a greater cooling capacity in milling of Ti-6Al-4V compared to a high pressure emulsion cooling. Multiple studies found that milling the two phase $(\alpha+\beta)$ Ti-6Al-4V alloy with $\mathrm{LCO}_{2}$ resulted in increased tool life in comparison to conventional soluble oil coolants [Sadik 2016; 2017], [Pittalà 2018]. Sadik (2017) demonstrated that face milling of Ti-6Al-4V with $\mathrm{LCO}_{2}$ delivered through a machine tool spindle under a pressure of 50 bar has a positive influence on tool life compared to the conventional oil-based coolant. However, this was only noticed for relatively low cutting speeds and feed rates. In addition, no significant differences between cooling methods were observed at higher cutting speed $(100 \mathrm{~m} / \mathrm{min})$ and feed rate $(0.15-0.20 \mathrm{~mm} /$ tooth $)$. The same authors have looked at the effect of different $\mathrm{CO}_{2}$ flow rates on the tool life in milling of Ti-6Al-4V, finding a limited influence on the growth of flank wear with cutting time at cutting speed $V_{c}=80 \mathrm{~m} / \mathrm{min}$ and feed rate $f_{z}=0.15$ $\mathrm{mm}$ /tooth [Sadik 2016]. In turn, in climb milling of Ti-6Al-4V with solid carbide end mills, the results showed that the position and diameter of the coolant holes have a significant effect on tool flank wear [Pittalà 2018]. Similarly to Sadik (2016), no significant difference in tool wear between $\mathrm{LCO}_{2}$ and conventional soluble oil coolant was observed after increasing the cutting speed from $90 \mathrm{~m} / \mathrm{min}$ to $130 \mathrm{~m} / \mathrm{min}$ [Pittalà 2018].

The studies show that generally, $\mathrm{CO}_{2}$ can effectively remove the heat from the cutting zone at moderate cutting speeds and feeds. However, significantly increased notch wear is observed at higher cutting speeds. The MRR increases to a certain maximum with the increase in depth of cut and a further increase in the material removal rate is typically limited either by the dynamic stability of a machine tool or due to maximum spindle speed and spindle power [Smith 2000]. Therefore, the desirable MRR range to achieve an acceptable surface finish can only be achieved for a specific combination of cutting parameters. The optimal cutting conditions are generally in a narrow range of cutting speeds of less than $40 \mathrm{~m} / \mathrm{min}$ to be within the limit of process stability [Bach 2012].

This paper is focused on the effect of the key process variables (cutting speed, feed rate and depth of cut) on the surface integrity in the milling of two phase $(\alpha+\beta)$ Ti-6Al-4V. Various combinations of these cutting parameters on surface integrity were investigated considering the high cutting speed limitations and its negative impact on tool wear and surface finish.

The study has been carried out using various cooling methods such as $\mathrm{scCO}_{2}, \mathrm{scCO}_{2}$ with Minimum Quantity Lubrication ( $\mathrm{scCO}_{2}+\mathrm{MQL}$ ), conventional soluble oil-based flood coolant and high pressure (HP) coolant.

The results obtained from this study are discussed in terms of the mean values of cutting forces and residual stress. 
The residual stress and cutting force data were analysed and linked to microstructural analysis and microhardness.

\section{EXPERIMENTAL WORK}

\subsection{Experimental setup}

The material investigated in this study was two phase $(\alpha+\beta)$ Ti-6Al-4V alloy (Grade 5) in annealed condition. The chemical composition of the workpiece material is given in Tab. 1.

Tab. 1: Chemical composition of Ti-6Al-4V workpiece.

\begin{tabular}{|c|c|c|}
\hline Workpiece & Element & Composition (wt.\%) \\
\hline \multirow{7}{*}{ Ti-6Al-4V } & $\mathrm{C}$ & 0.008 \\
\cline { 2 - 3 } & $\mathrm{Al}$ & 6.26 \\
\cline { 2 - 3 } & $\mathrm{Fe}$ & 0.21 \\
\cline { 2 - 3 } & $\mathrm{H}$ & 0.0007 \\
\cline { 2 - 3 } & $\mathrm{N}$ & 0.009 \\
\cline { 2 - 3 } & $\mathrm{O}$ & 0.143 \\
\cline { 2 - 3 } & $\mathrm{V}$ & 4.18 \\
\cline { 2 - 3 } & $\mathrm{Ti}$ & $\mathrm{Bal}$. \\
\cline { 2 - 3 } & Residual & $<0.40$ \\
\hline
\end{tabular}

Four plates of $196 \times 133 \times 34 \mathrm{~mm}$ were used in the climb milling experiments. The plates were held in a HILMA NC 160 vice and then the vice was clamped to a Kistler Type $9255 \mathrm{C}$ force plate, which has the dimensions of $500 \times 500$ $\mathrm{mm}$, as shown in Fig. 1.
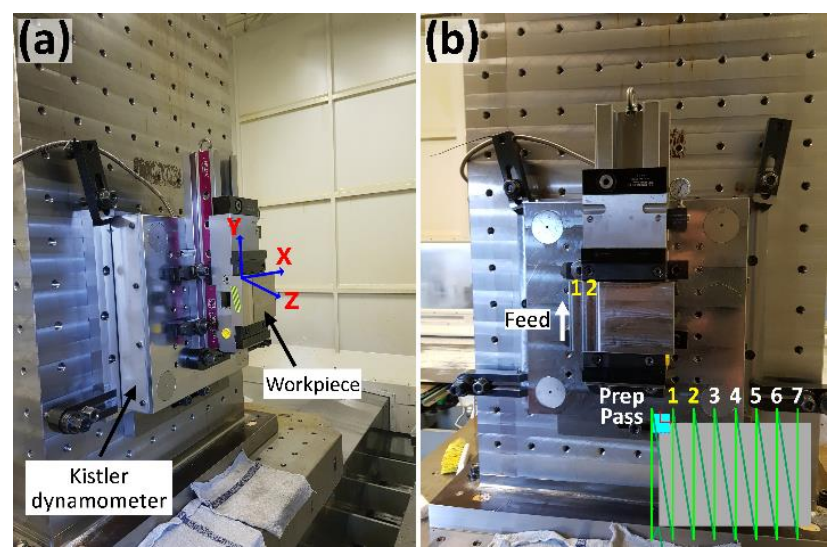

Fig. 1: Machining setup: (a) side view, (b) front view and definition of the cutting strategy.

A Starrag Heckert HEC1800 horizontal machining centre, with 4-axis traversing table and a column mounted spindle, was used in this work. The machine tool was retrofitted with a commercially available $\mathrm{scCO}_{2}$ unit (manufactured by Fusion Coolant Systems) to provide a mixture of supercritical $\mathrm{CO}_{2}$ and $\mathrm{MQL}$ through the machine tool spindle directly to the cutting zone.

The MQL lubricant mixed with $\mathrm{scCO}_{2}$ at the flow rate of 2 $\mathrm{ml} / \mathrm{min}$ was NuCut Plus soybean oil. The soluble oil-based fluid was HOCUT 795N (both in case of flood and highpressure coolant) (Tab. 2).
Tab. 2: Cooling strategies used in milling of Ti-6Al-4V.

\begin{tabular}{|c|c|c|}
\hline Coolant type & $\begin{array}{c}\text { Coolant supply } \\
\text { pressure }\end{array}$ & Flow rate \\
\hline $\mathrm{scCO}_{2}$ & $140 \mathrm{bar}$ & $39 \mathrm{~kg} / \mathrm{hr}$ \\
\hline $\mathrm{scCO}_{2}+\mathrm{MQL}$ & $140 \mathrm{bar}$ & $39 \mathrm{~kg} / \mathrm{h}+2 \mathrm{ml} / \mathrm{min}$ \\
\hline flood & $6 \mathrm{bar}$ & $50 \mathrm{l} / \mathrm{min}$ \\
\hline high pressure & $70 \mathrm{bar}$ & $14 \mathrm{l} / \mathrm{min}$ \\
\hline
\end{tabular}

A full factorial (mixed level) design was selected. A total of 48 runs were carried out (12 runs per each coolant). Tab. 3 lists all the input factors and their corresponding levels. The cutting tool used was a $42 \mathrm{~mm}$ diameter high feed 419042C4-14M face mill (Sandvik Coromant) in a C4-390.410100 holder equipped with three 419R-1405E-MM S40T grade cutting inserts. A new cutting edge was used every time the cutting parameters or cooling methods were varied. The coolants $\left(\mathrm{scCO}_{2}, \mathrm{scCO}_{2}+\mathrm{MQL}\right.$, flood and $\left.\mathrm{HP}\right)$ were delivered to the cutting edge zone through the same three coolant supply ports. Flood coolant was supplied externally at a rate of $50 \mathrm{l} / \mathrm{min}$. In terms of $\mathrm{scCO}_{2}$ and $\mathrm{scCO}_{2}+\mathrm{MQL}$, the ports were modified (threaded) to accommodate M4 grub screws of specific hole diameter. In this work the $\varnothing 0.25 \mathrm{~mm}$ grub screws were used which, at $\mathrm{CO}_{2}$ pressure of 140 bar, resulted in a flow rate of $\mathrm{scCO}_{2}$ of $39 \mathrm{~kg} / \mathrm{hr}$. Flood and HP cooling were run without M4 grub screws.

Tab. 3: Factors and corresponding levels used in the Design of Experiments.

\begin{tabular}{|c|c|}
\hline Factors & Levels \\
\hline Feed rate $[\mathrm{mm} /$ tooth] & $0.3 ; 0.6 ; 0.9$ \\
\hline Cutting speed [m/min] & $30 ; 60$ \\
\hline Depth of cut [mm] & $0.5 ; 1.0$ \\
\hline Type of coolant & $\begin{array}{c}\text { flood; high pressure; } \mathrm{scCO}_{2} ; \\
\text { scCO }\end{array}$ +MQL \\
\hline
\end{tabular}

\subsection{Machined surface characterisation}

The surface finish after milling was measured along the feed direction with a stylus-type surface roughness tester (Mutitoyo SJ 410). The evaluation length of the roughness profile was $40 \mathrm{~mm}$. The Ra values were calculated as the mean of three individual measurements taken every $3 \mathrm{~mm}$ spacing in the transverse direction. The residual stress (RS) was evaluated using a Proto LXRD measurement system. The residual stresses were determined by the $\sin ^{2} \Psi$ method based on the strains along the [311] direction at an angle $(2 \theta)$ of $155.2^{\circ}$. The elastic constants $S_{1}{ }^{(h k l)}$ and $1 / 2 \mathrm{~S}_{2}(\mathrm{hkl})$ used to determine the residual stresses were $1.41 \times 10^{-6}[1 / \mathrm{MPa}]$ and $6.25 \times 10^{-6}[1 / \mathrm{MPa}]$, respectively. The RS measurements were made in both transverse $\left(0^{\circ}\right)$ and longitudinal $\left(90^{\circ}\right)$ directions. The values of $\mathrm{RS}$ are the mean of six individual measurements. Then, the workpiece plates were cut with an abrasive cut-off machine into small pieces for microhardness measurements and microstructural analysis in longitudinal and transverse feed directions. The samples were ground and polished manually in the crosssection direction. Finally, the samples were etched for five seconds with a mixture of ammonium hydrogen difluoride $\left(\mathrm{NH}_{4} \mathrm{HF}_{2}\right)$ and water diluted down to $\mathrm{NH}_{4} \mathrm{HF}_{2}: \mathrm{H}_{2} \mathrm{O}$ ratio of $1: 10$ to reveal the deformed grain structure (surface defects) after Ti-6Al-4V high feed milling. The microhardness measurements were performed using a TUKON 2500 automated hardness tester under a load of $50 \mathrm{~g}$ with a dwell time of $15 \mathrm{~s}$. Vickers microhardness profiles were measured on the cross section along the longitudinal direction using an average of five readings for each profile. The Vickers microhardness was measured at

MM Science Journal | 2019 | Special Issue on HSM2019 
about $30 \mu \mathrm{m}$ from the surface to depth. For microstructural analysis, a Phenom XL scanning electron microscope (SEM) with an energy dispersive $\mathrm{X}$-ray spectroscopy (EDS) was used to take images of the machined surface.

\section{RESULTS AND DISCUSSION}

\subsection{Cutting forces}

The coefficient plot for cutting forces measured in the experiments is shown in Fig. 2. It shows that the main variables affecting the thrust and feed forces are the depth of cut followed by the feed rate. The opposite effect was observed for the cross-feed force, with feed rate having the highest influence (Fig. 2a). It can also be seen that the type of coolant has an influence on the cutting forces. The feed force and cross-feed force were found to increase with increased cooling efficiency and the addition of MQL. The highest cutting forces were obtained in the feed direction.

(a)

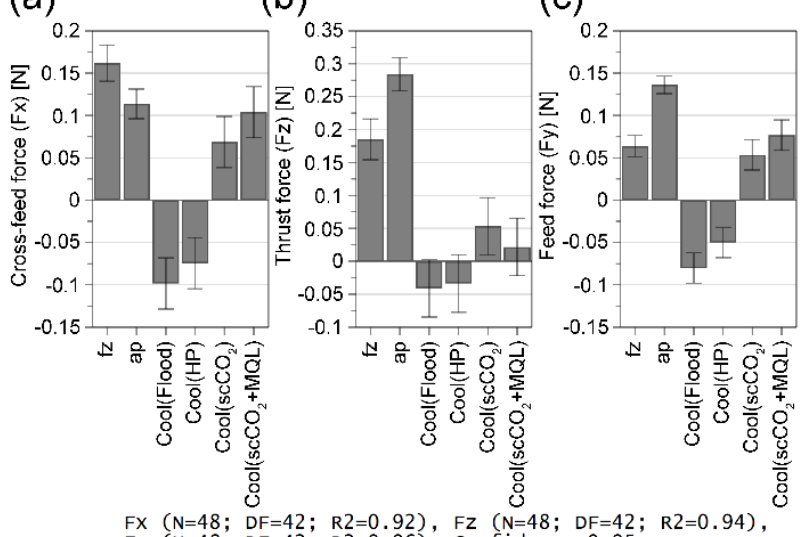

$\mathrm{FX}(\mathrm{N}=48 ; \mathrm{DF}=42 ; \mathrm{R} 2=0.92), \mathrm{FZ}(\mathrm{N}=48 ; \mathrm{DF}=42 ; \mathrm{R} 2=0.94)$,

Fig. 2: Regression coefficient plot for cutting forces: (a) cross-feed force, (b) thrust (axial) force and (c) feed force.

Fig. 3 shows the mean values of the feed force at various cutting conditions measured during the experiments for different cooling methods.

(a)
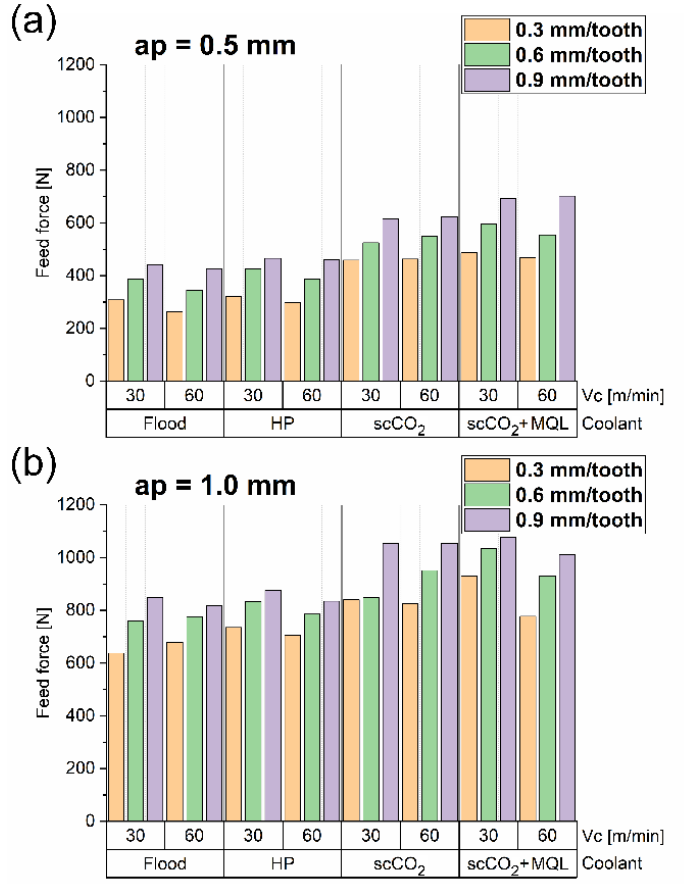

Fig. 3: Variations of feed force with depth of cut (a) 0.5 $\mathrm{mm}$ and (b) $1.0 \mathrm{~mm}$.
The change in feed force was significantly affected by the depth of cut, and similarly by the feed rate, regardless of the cooling method. No significant changes in feed force values were observed when the cutting speed increased from 30 $\mathrm{m} / \mathrm{min}$ to $60 \mathrm{~m} / \mathrm{min}$ at $0.5 \mathrm{~mm}$ depth of cut (Fig. 3a). It can be seen that milling of Ti-6Al-4V with $\mathrm{ScCO}_{2}$ and $\mathrm{scCO}_{2}+\mathrm{MQL}$ resulted in higher cutting force values compared to conventional soluble oil coolants (flood and HP coolant). The lower cutting forces with flood and HP coolants are most likely due to the thermal softening of the workpiece caused by the temperature rise. The reason for this can be the low thermal conductivity of Ti-6Al-4V and low cooling efficiency of flood/HP coolant in comparison to $\mathrm{ScCO}_{2}$. The higher cooling efficiency of $\mathrm{scCO}_{2}$ resulted in increased cutting forces because of a possible work hardening and an increase in strain rate. This does not seem to be the case at higher cutting speed as a decrease in cutting force values at $V_{c}=60 \mathrm{~m} / \mathrm{min}$ with $\mathrm{scCO}_{2}+\mathrm{MQL}$ $\left(a_{p}=1.0 \mathrm{~mm}\right)$ was observed.

\subsection{Residual Stress}

The residual stress was evaluated in the feed direction of the tool (longitudinal, $90^{\circ}$ ) and perpendicular to the direction of feed (transverse, $0^{\circ}$ ). Fig. 4 presents the regression coefficients for the residual stress model. The type of coolant input factor was not statistically significant, hence it is not part of the model. It was observed that the feed rate has a positive or negative effect on the response in the longitudinal and transverse direction, respectively. It means that the residual stress increases in the longitudinal direction with an increase in feed rate. The opposite was seen for residual stress in the transverse direction. Therefore, more compressive residual stresses are developed near the surface in the transverse direction. This can potentially result in surface alterations induced by a mechanical load in the transverse direction.

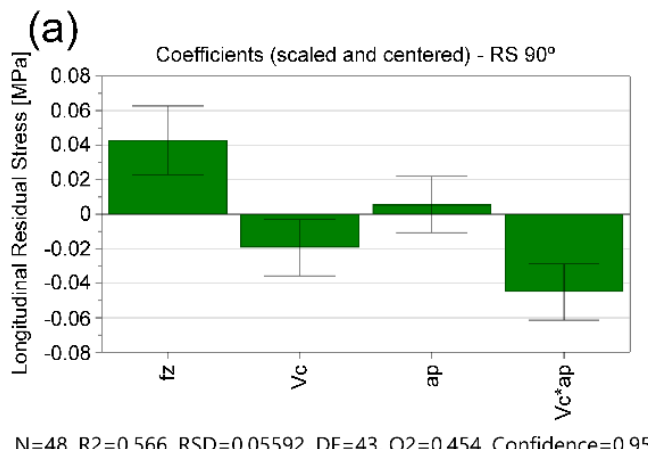

(b)

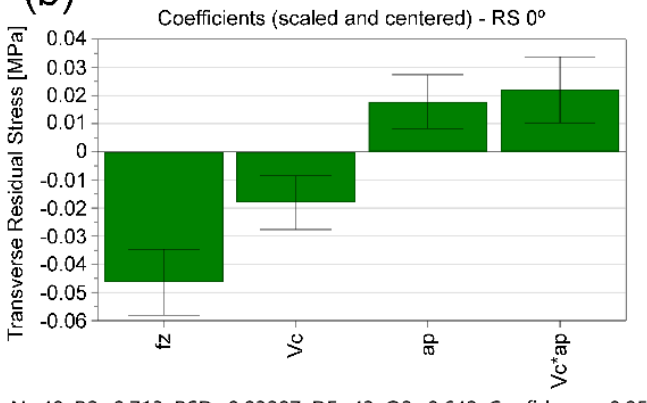

$\mathrm{N}=48, \mathrm{R} 2=0.713, \mathrm{RSD}=0.03287, \mathrm{DF}=43, \mathrm{Q} 2=0.642$, Confidence $=0.95$

Fig. 4: Regression coefficient plot for the influence of variables on residual stress in the (a) longitudinal and (b) transverse directions.

Cutting speed had a lower impact on residual stresses compared to feed rate (nearly equal positive effect in the two directions). In Fig. 4, the $\mathrm{R}^{2}$ and $\mathrm{Q}^{2}$ values were calculated at the $95 \%$ confidence level using the Multiple 
Linear Regression (MLR) method. The $R^{2}$ and $Q^{2}$ values calculated for residual stress in the transverse direction (RS $\left.0^{\circ}\right)$ were 0.713 and 0.642 , respectively.

Fig. 5 shows the response contour plots for residual stress in the longitudinal and transverse directions. (a)

\section{ap $=0.5 \mathrm{~mm}$}

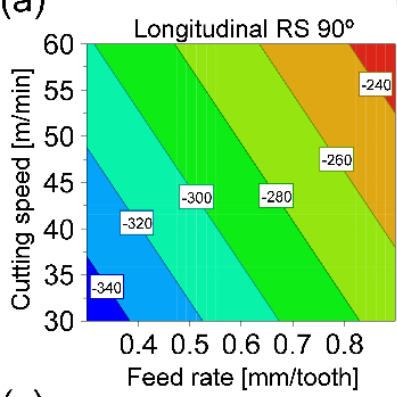

(c)

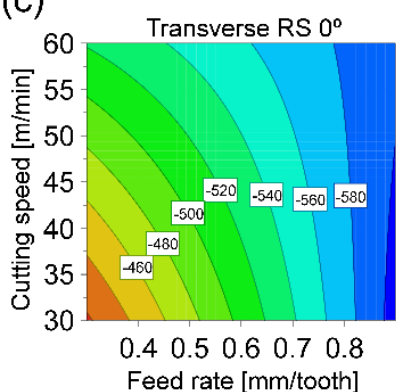

(d)

\section{ap $=1.0 \mathrm{~mm}$}

(b)
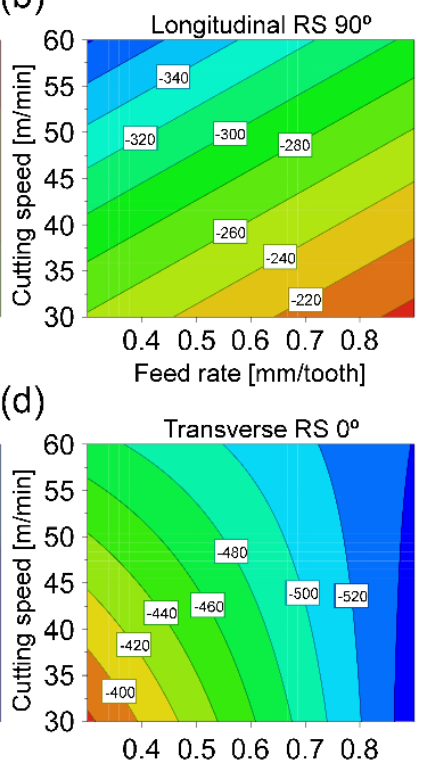

Feed rate [mm/tooth]
Fig. 5: Response contour plot: effect of cutting speed and feed rate on residual stress in relation to depth of cut.

All the evaluated residual stresses were compressive. The results show that the magnitude and distribution of residual stress change with increasing depth of cut. The compressive residual stress values were marginally depth of cut the compressive residual stresses are reduced in magnitude due to the thermal deformation [Ji 2018]. In addition, from Fig. 5 it can be observed that the residual stress values in the longitudinal direction are, in general, lower than in the transverse direction. Also, the pattern of residual stress distribution is changed in the longitudinal direction with increased depth of cut. It is believed that the main mechanism that contributes to the increased residual stress values in the longitudinal direction is related to the thermal effects in the workpiece (the thermal induced residual stress). At higher depth of cut (Fig. 5b), less heat generated at high speeds is dissipated from the cutting zone to the machined surface. As explained by Edkins et al. (2014), this can result in increased mechanical plastic deformation mechanism, which in turn, tends to induce compressive residual stress. Therefore, the pattern change of the contour lines of the response was observed for higher depth of cut.

\subsection{Microstructure}

Fig. 6 shows the SEM micrographs at the same magnification (4000x) of cross-sections along the longitudinal (Fig. 6a) and transverse (Fig. 6b) directions of machined surfaces.

It compares microstructure of Ti-6Al-4V alloy machined with the assist of various types of coolant. It was found that a type of coolant used in milling of Ti-6Al-4V can influence the microstructure of this alloy. The workpiece microstructure consists of the two phases identified using SEM/EDS analysis. These are $\alpha$ - and $\beta$-phases with their stabilising alloying elements, $\mathrm{Al}$ and $\mathrm{V}$, respectively (EDS spectrum in Fig. 6). The $\beta$ phase in Fig. 6 is distributed along grain boundaries of $\alpha$ phase. The relative differences in the distribution of the $\alpha$ - and $\beta$ phases in Ti-6Al-4V were observed. The microstructural changes were determined by comparison of the microstructures of the machined (a)

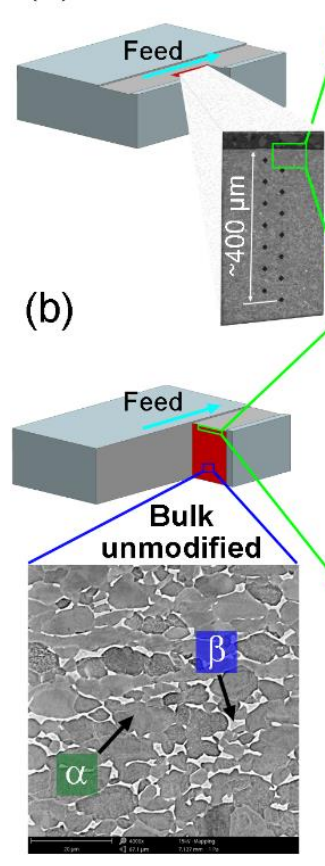

Flood
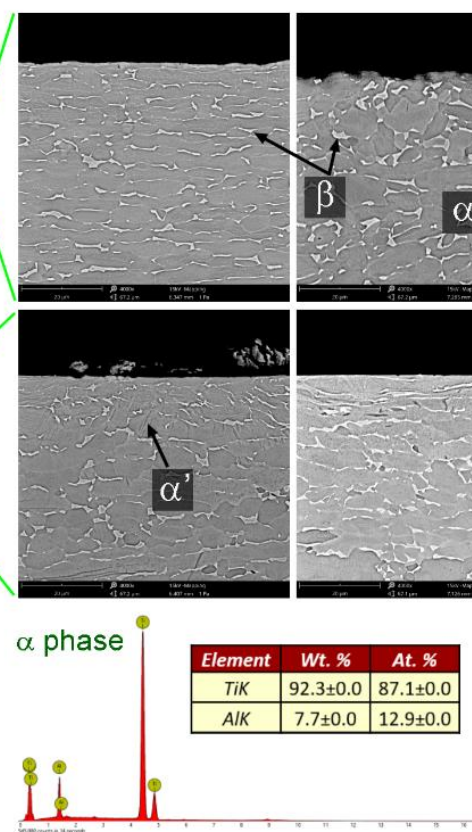

HP coolant
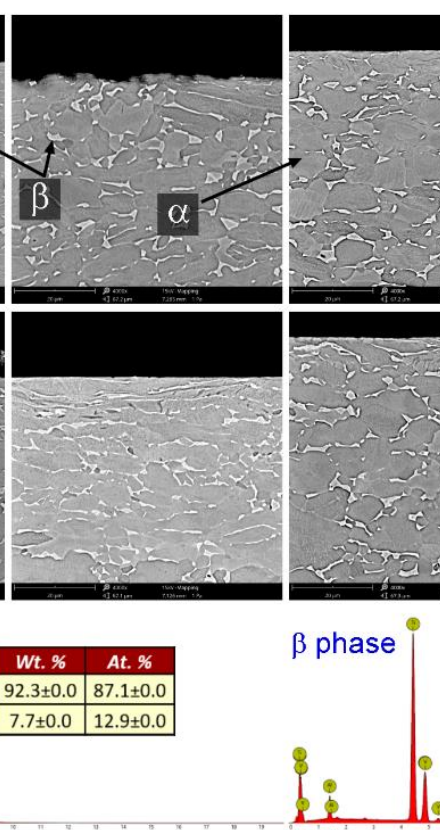

$\mathrm{scCO}_{2}$

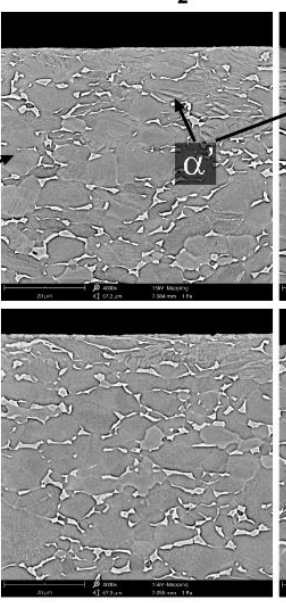

$\mathrm{scCO}_{2}+\mathrm{MQL}$
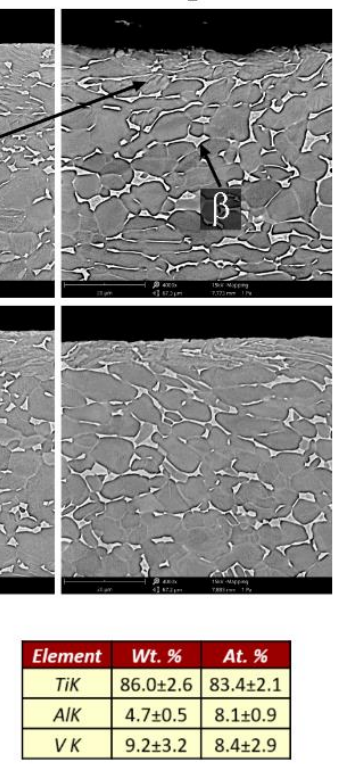

Fig. 6: SEM micrographs of (a) longitudinal and (b) transverse cross-sections of the Ti-6Al-4V workpiece surfaces after milling $\left(f_{z}=0.60 \mathrm{~mm} /\right.$ tooth, $\left.V_{c}=60 \mathrm{~m} / \mathrm{min}, a_{p}=1.0 \mathrm{~mm}\right)$ for various coolant types.

reduced at a higher feed rate. Also, Ji et al. (2018) found that increasing the axial depth of cut results in more tensile stress. The authors explained that with an increase in the surfaces against the not-machined bulk material region. It was observed that the microstructure of Ti-6Al-4V is strongly influenced by the level of cooling efficiency. 
The significant difference of $\beta$-phase morphology in Ti-6Al$4 \mathrm{~V}$ along the longitudinal direction was observed between the samples machined with flood coolant and $\mathrm{scCO}_{2}+\mathrm{MQL}$. As seen in Fig. 6a, milling with flood coolant results in a finer platelet $\beta$ structure within the $\alpha$ grains. By comparing the microstructure of the machined surface after milling with $\mathrm{scCO}_{2} \mathrm{MQL}$ and unmodified bulk material microstructure, no significant difference could be observed. The opposite was found for flood coolant. In addition, no major differences were found between the effect of high pressure coolant and $\mathrm{scCO}_{2}$ on the microstructure of Ti-6Al-4V.

It is believed that the cutting forces and heat generated during milling of Ti-6Al-4V are the main reasons for the observed changes in microstructure. A less significant influence of coolant type on microstructure was observed in the transverse direction compared to the longitudinal direction. From Fig. 5 it can be seen that more compressive residual stress values were obtained in the transverse direction. This result can suggest that the effect of temperature in the transverse direction is weaker compared to the longitudinal direction. Some surface layer alterations were observed in transverse cross-sections (Fig. 6b).

In addition, the feed force acts primarily in the longitudinal direction. The applied cutting forces and temperature effects caused by reduced efficiency of flood coolant in the removal of heat from the cutting zone can possibly cause phase transformation in Ti-6Al-4V. In the work conducted by Sun et al. (2016), the volume fraction of $\alpha$-phase increased due to the phase transformation from $\beta$ - to $\alpha$ phase in the machined surface under a slow cooling rate. In Fig. 6, however, there was no clear indication that the volume fraction of $\alpha$-phase increased for flood coolant. There is no clear evidence that the phase transformation occurred. More research is needed to evaluate cutting temperature to see if it is in a range of phase transformation in Ti-6Al-4V which is about $880^{\circ} \mathrm{C}$ [Nouari 2014]. It can be stated that $\mathrm{scCO}_{2}+\mathrm{MQL}$ provides the most effective cooling in the milling of Ti-6Al-4V. This can result in an improvement of surface integrity including microstructural changes in the near-surface layer compared to $\mathrm{scCO}_{2}$ (without MQL) and other coolants (Fig. 6). It can be argued that the addition of a minimum quantity of lubricant (MQL) reduces friction between the cutting tool and the workpiece. This results in less heat generated during cutting which, in combination with $\mathrm{ScCO}_{2}$, gives the best results in terms of cooling efficiency. The microstructural changes can also be attributed to shear deformation in the strain-hardened workpiece.

Fig. 7 shows SEM micrographs of the machined surface layer after milling of Ti-6Al-4V with $\mathrm{scCO}_{2}+\mathrm{MQL}$ for different tool feed rates. The variable investigated was feed rate while cutting speed and depth of cut were kept constant. From Fig. 7 it can be seen that no significant differences can be found in longitudinal cross-section micrographs (Fig. $7 \mathrm{a}$ ). In the transverse direction (Fig. 7b), some surface alterations can be observed with an increase in feed rate from $0.3 \mathrm{~mm} /$ tooth to $0.9 \mathrm{~mm} /$ tooth. In addition, the volume fraction of the primary $\alpha$ - and $\beta$-phases in Ti-6Al-4V remained unaffected and the microstructure is homogenous. The obtained results showed that alterations of the surface can be induced by increased compressive residual stress under mechanical loads in the transverse direction. The cutting forces increased with increasing feed rate resulting in higher residual stresses. Significantly higher residual stress values were observed in a transverse direction to the direction of feed rate which implied surface deformations.

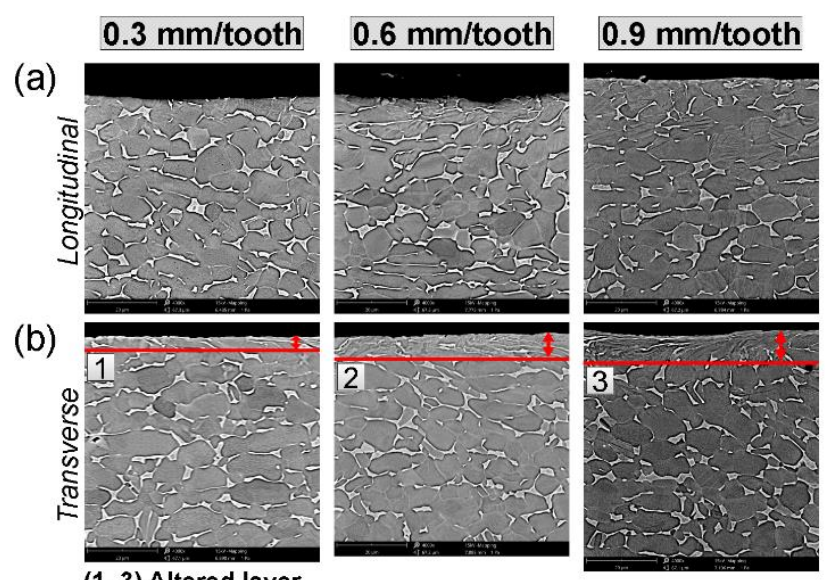

(1-3) Altered layer

Fig. 7: SEM micrographs of machined surfaces with $s c \mathrm{SO}_{2}+\mathrm{MQL}$ at different feed rates and constant $V_{c}=60$ $\mathrm{m} / \mathrm{min}$ and $a_{p}=1 \mathrm{~mm}$. (a) longitudinal and (b) transverse cross-sections.

Small $\alpha$ ' precipitates can also be seen when looking at the microstructures in Figs. 6 and 7. However, further research is needed to identify the $\alpha$-phase transformation kinetics which could potentially further decompose to the $\alpha$ - and $\beta$ phases during stress relieving treatment [Patil 2016].

\subsection{Microhardness and surface roughness}

To investigate the effect of machining induced microstructural changes in Ti-6Al-4V on surface integrity, the microhardness and the surface roughness were measured. Fig. 8 shows the microhardness profiles along the longitudinal direction. From Fig. 8 it can be seen that no significant changes in near surface microhardness can be observed regardless of the type of coolant used in milling of Ti-6Al-4V. Also, the increase in feed rate does not affect the microhardness of the machined surface in the longitudinal direction $\left(\mathrm{scCO}_{2}+\mathrm{MQL}\right)$.

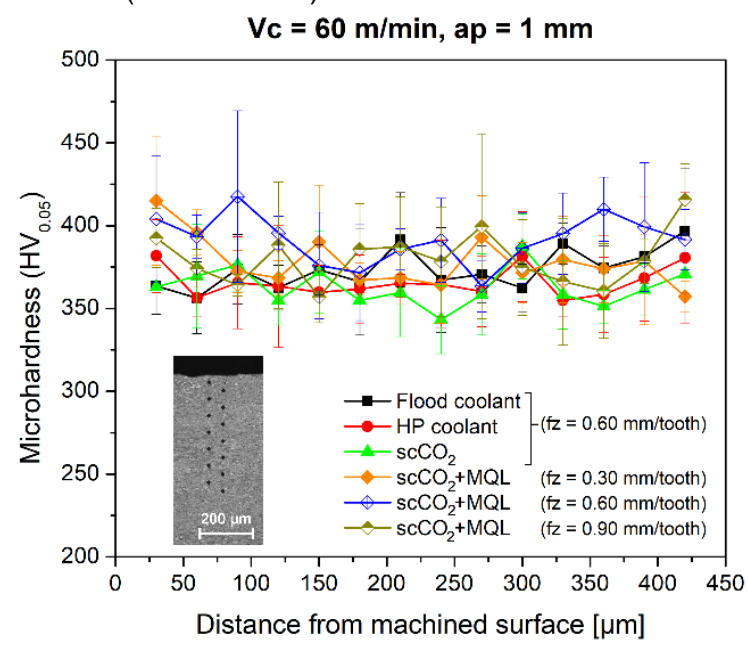

Fig. 8: Microhardness profiles along the longitudinal direction of machined surfaces.

Fig. 9 shows the mean surface roughness $(\mathrm{Ra})$ values. 


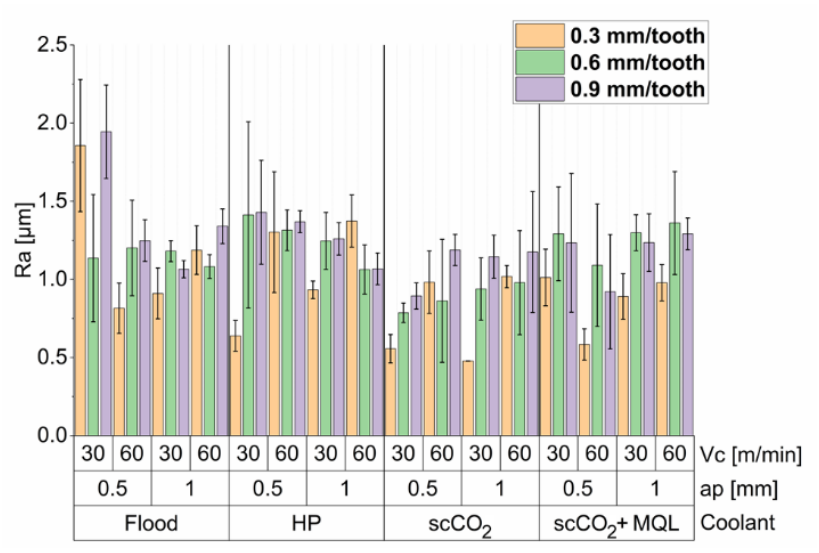

Fig. 9: Surface roughness (Ra) after milling of Ti-6Al-4V at various cutting conditions.

Surface roughness was measured directly on the machined surface after milling (before cutting oriented specimens for microstructural analysis). There are significant changes in $\mathrm{Ra}$ values depending on the cutting conditions being used. Feed rate has the strongest influence on surface roughness followed by the cutting speed and then the depth of cut. Also, higher $\mathrm{Ra}$ values were observed for flood coolant compared to $\mathrm{scCO}_{2}$ and $\mathrm{scCO}+\mathrm{MQL}$ at a low feed rate. It was expected that the surface roughness will be decreased after milling of Ti-6Al-4V with flood coolant. This can be related to the phase transformation in $\mathrm{Ti}$. The increase in surface roughness and phase transformation during milling with flood coolant can affect creep strength of the machined surface, and thus corrosion resistance. However, further research is needed to provide clear evidence of the effectiveness of $\mathrm{scCO}_{2}$ in milling of Ti-6Al-4V.

\section{SUMMARY AND CONCLUSIONS}

The two phase $(\alpha+\beta)$ Ti-6Al-4V alloy was used in climb milling to investigate the influence of cutting conditions and type of coolant on surface integrity. The effectiveness of a new cooling method in high feed milling of Ti-6Al-4V with supercritical $\mathrm{CO}_{2}$ was assessed mainly by means of microstructure analysis and analysis of residual stress in the longitudinal and transverse directions. Also, analysis of variation of cutting forces, microhardness, and surface roughness were carried out to determine the influence of $\mathrm{ScCO}_{2}$ either with or without MQL on surface integrity in milling of Ti-6Al-4V.

Based on experimental results the following conclusions were drawn:

- Machining with $\mathrm{scCO}_{2}$ and $\mathrm{scCO}_{2}+\mathrm{MQL}$ resulted in higher cutting force values compared to flood coolant and HP coolant, indicating strain hardening behaviour and possible martensite $\left(\alpha^{\prime}\right)$ formation at the high cooling rate with $\mathrm{scCO}_{2}$ and $\mathrm{scCO}_{2}+\mathrm{MQL}$. However, no strong evidence of microhardness increase was found against other coolants.

- Compressive residual stress was introduced regardless of the type of coolant being used. The magnitude of the residual stress depended on the cutting conditions with the biggest influence of the tool feed rate on the residual stress.

- It was found that the type of coolant influences the near surface microstructure of Ti-6Al-4V. The microstructural difference between flood coolant and $\mathrm{scCO}_{2}+\mathrm{MQL}$ depends on the strain and temperature effects. In milling with flood coolant, the workpiece undergoes deformation at a high cutting temperature which alters the microstructure. The high cutting temperature can possibly cause the phase transformation in machining with flood coolant. No major differences in microstructure were found between HP and $\mathrm{scCO}_{2}$.

- No significant changes in surface microhardness in the longitudinal direction were observed in all types of coolant used in milling of Ti-6Al-4V.

- In comparison with $\mathrm{scCO}_{2}$ and $\mathrm{scCO}_{2}+\mathrm{MQL}$, higher mean roughness $(\mathrm{Ra})$ values were observed after milling of Ti-6Al-4V with flood coolant at low feed rate.

- The most effective cooling was provided when milling with $\mathrm{scCO}_{2}+\mathrm{MQL}$. No deterioration of the surface integrity in terms of increased residual stress and microhardness or surface cracking was observed. In addition, no evidence of microstructural changes was observed for $\mathrm{scCO}_{2}+\mathrm{MQL}$.

\section{ACKNOWLEDGMENTS}

Authors would like to acknowledge financial support from the High Value Manufacturing Catapult (HVMC), UK.

\section{REFERENCES}

[Pervaiz 2014] S. Pervaiz, A. Rashid, I. Deiab, M. Nicolescu, Influence of tool materials on machinability of titanium- and nickel-based alloys: a review, Materials and Manufacturing Processes, 29 (2014) 219-252

[Busch 2016] K. Busch, C. Hochmuth, B. Pause, A. Stoll, R. Wertheim, Investigation of cooling and lubrication strategies for machining high-temperature alloys, Procedia CIRP 41 (2016) 835-840

[Pušavec 2019] F. Pušavec, D. Grguraš, M. Koch, P. Krajnik, Cooling capability of liquid nitrogen and carbon dioxide in cryogenic milling, CIRP Annals - Manufacturing Technology 68 (2019) 73-76

[Sadik 2017] M.I. Sadik and S. Isakson, The role of PVD coating and coolant nature in wear development and tool performance in cryogenic and wet milling of Ti-6Al-4V, Wear 386-387 (2017) 204-210

[Sadik 2016] M.I. Sadik, S. Isakson, A. Malakizadi and L. Nyborg, Influence of coolant flow rate on tool life and wear development in cryogenic and wet milling of Ti-6Al-4V, Procedia CIRP 46 (2016) 91-94

[Pittalà 2018] G.M. Pittalà, A study of the effect of $\mathrm{CO}_{2}$ cryogenic coolant in end milling of Ti-6Al-4V, Procedia CIRP 77 (2018) 445-448

[Smith 2000] S. Smith, W.R. Winfough, H.J. Borchers, Power and stability limits in milling, Annals of the CIRP 49 (2000) 309-312

[Bach 2012] P. Bach, G. Trmal, P. Zeman, J. Vana and J. Maly, High performance titanium milling at low cutting speed, Procedia CIRP 1 (2012) 226-23

[Nouari 2014] M. Nouari, H. Makich, On the physics of machining titanium alloys: interactions between cutting parameters, microstructure and tool wear, Metals 4 (2014) 335-358

[Sun 2016] Y. Sun, B.Huang, D.A. Puleo, J. Schoop, I.S. Jawahir, Improved surface integrity from cryogenic machining of Ti-6Al-7Nb alloy for biomedical applications, Procedia CIRP 45 (2016) 63-66 
[Ji 2018] Ch. Ji, S. Sun, B. Lin, J. Fei, Effect of cutting parameters on the residual stress distribution generated by pocket milling of 2219 aluminum alloy, Advances in Mechanical Engineering 10(12) (2018) 1-15

[Edkins 2014] K.D. Edkins, N.J. van Rensburg, R.F. Laubscher, Evaluating the subsurface microstructure of machined Ti-6Al-4V, Procedia CIRP 13 (2014) 270-275

[Patil 2016] S. Patil, S. Kekade, K. Phapale, S. Jadhav, A. Powar, A. Supare, R. Singh, Effect of $\alpha$ and $\beta$ phase volume fraction on machining characteristics of titanium alloy Ti6Al4V, Procedia Manufacturing 6 (2016) 63-70 